\title{
Trilingualism and Foreign Language Proficiency
}

\author{
Zargham Ghabanchi \\ English Department, Ferdowsi University of Mashhad \\ P.O. Box 91779-48974, Park Square, Mashhad, Iran \\ Tel: 98-511-879-6829_E-mail: ghabanchi@um.ac.ir
}

Received: June 5, 2011

Accepted: August 12, $2011 \quad$ Published: October 1, 2011

doi:10.5430/wje.v1n2p181

URL: http://dx.doi.org/10.5430/wje.v1n2p181

\begin{abstract}
The delicate issue of the development of the monolingual, bilingual, and trilingual speakers learning English as a foreign language was considered in this study. The idea of learning a foreign language and the preparation for participating in the TOEFL test was combined to determine the degree of achievement and progress between monolingual, bilingual and trilingual speakers. Consequently, proposals to integrate the study of foreign language learning and trilingualism have been made as a means of describing some of the ways in which monolingual, bilingual, and trilingual speakers differ in their progress of mastering a foreign language which lead to their success in the TOEFL exam.

This study was mainly carried out to test this presupposition that those who have acquired more than one native language might be more successful in learning another one after puberty. The subjects of the study consist of sixty-four students: thirty monolingual, sixteen bilingual, and sixteen trilingual students studying English as a foreign language with the aim of passing the TOEFL test. Their native languages were Persian, Persian and Kurdish or Turkish, Persian and Kurdish and Turkish. The subjects were randomly placed into two groups. The lecturers were the same. The covered topics were grammar, listening and reading comprehension. A pre-test was carried out before the intensive course and a TOEFL test was the final step of the instruction period. The teaching period was four months full-time instruction.

The findings did not show the superiority of bilingual and trilingual speakers over the monolingual ones. In fact, the monolingual subjects did slightly better than the other groups. However, the t-test and other statistical analysis proved that the difference is not significant. Consequently, it is possible to infer that after the age of puberty having more than one native like language cannot be of great help in learning a foreign language. The implications of the results might be in methodology addressed in terms of appropriate training content, and the needs for an educationally and linguistically methodology as effective means in teaching English as a foreign language.
\end{abstract}

Keywords: Monolingual, Bilingual, Trilingual speakers, Achievement, Persian, Persian and Kurdish, Puberty

\section{Introduction}

A great deal of attention has recently been paid to third language learning and acquisition. This is partly due to the growing need to be competent in languages used in wider communication (Cenoz \& Genesee, 1998) and to 'the exigencies of globalization', which encourage people to have 'another language of significance in the region, and an international language' besides their first language (Clyne, 1997, p. 96).

In general, ‘...the process of acquiring several non-native languages (i.e. multilingual acquisition) and the final result of this process (multilingualism) have received relatively little attention in the scientific research in comparison to second language acquisition and bilingualism' (Cenoz \& Genesee, 1998, p. 16).

Also several areas in the acquisition of a non-native language beyond a second language (i.e. an L3) have not received sufficient attention from acquisition researchers and teaching practitioners. Among those areas of relevance to L3 acquisition is that of text-level proficiency. This seems to pose numerous problems to learners of both L2 and L3. Although the acquisition of an L3 has some distinct features, since it involves elements that play a role in the processing of more than two linguistic systems, many language situations in the area of text-level proficiency, are similar for learners of L2 and L3 alike. In this regard, the paper addresses a number of essential text-level features of language acquisition that transcend differences (that may exist) between individual learners as well as in their environment.

Since the aim of learning a second language is to reach the state of bilinguality or trilinguality or even more, a better understanding of the mechanism involved in the development of bilinguality/ trilinguality should help us to understand second language acquisition. Learning a foreign language covers all cases of acquisition of a second language after the 
basic forms and functions of the first language have been mastered. This includes consecutive childhood bilinguality as well as adolescent and adult bilinguality, whether acquired through informal or formal learning. The present study was mainly carried out to test the presupposition that those who have acquired more than one native language might be more successful in learning another one after puberty.

Although there is an interest in the theoretical foundations on which the ideas of bilinguality and trilinguality as well as the idea concerning the second language teaching and learning rest, this study apart form handling a few definitions concerning bilingualism will consider only the question at hand which is does knowing more than one native-like language can be of extreme help in acquiring a foreign language?

\section{Dimensions and Measurement of Bilinguality}

\subsection{Definitions}

The concept of bilingualism seems at first sight to be non-problematic. According to Webster Dictionary (1961) bilingual is defined as having or using two languages especially as spoken with the fluency characteristic of a native speaker; a person using two languages especially habitually and with control like that of native speaker and bilingualism as 'the constant oral use of two languages.' This definition as well as the following ones can be applied to trilingual people; in other words, trilingual people are those with the capability of perfect mastering over three languages. Bloomfield (1935, p.35) defines bilingualism as 'the native-like control of two languages'. However, there are definitions which presume that any minimal competence about another language transfers the speaker to a bilingual person. Macnamara (1967) believes that a bilingual person is anyone who possesses a minimal competence in one of the four language skills (i.e. listening comprehension, speaking, reading, and writing in a language other than his mother tongue). In addition there are several modern definitions for the term trilingualism such as Hoffmann (1999) and Cenoz and Genesee (1998, p.2) on multilingualism have been suggested.

All of these definitions whether those which handle a perfect bilingual or the not perfect one are not without problems. It seems that almost all of them share one problem: all of the suggested definitions are identifier rather than definer. In other words, they do not define the bilingual/trilingual people they try to identify them on the bases of some observable features. For example, Hoffmann (1999) argues that trilingualism means the presence of three languages in one speaker and Cenoz and Genesee (1998, p.2) on multilingualism believe it to be the process of acquiring several non-native languages and the final result of this process. As is clear from the definitions, they just try to identify the trilingual people but not to define them. In addition, there is another problem concerning Hoffmann's definition, which is the notion of presence, which raises the question of threshold level. In other words, at which stage can we claim that the language is present or absent in a speaker. This problem from different perspective can be valid to Cenoz and Genesee's definition. The mentioned definitions also lack precision; they do not specify what is meant by native-like competence, which varies considerably within a unilingual population, nor by minimal proficiency in a second language. Can we exclude from the definitions of bilingual someone who possesses a very high competence in a second language without necessarily being perceived as a native speaker on account of a foreign accent? Can a person who has followed one or two courses in a foreign language without being able to use it in communication situations, or again someone who has studied Latin for six years, legitimately be called bilingual. Finally they argue about the final result of a process. This is extremely ambiguous: what do they mean by final result of a process and which process they are speaking about?

\section{Material and Methods}

\subsection{The subjects}

The geographical location of the University of Sabzevar provides a unique milieu for studying bilingual and trilingual students. This city is surrounded with different people speaking with different languages. A great number of them are non-native speaker of Persian. They learn Persian when they attend schools and start their formal education, since Persian is the official language of the country, the language of Mass media, and the language of instruction. Apart from Persian, there are around $16 \%$ of the suburb inhabitants speak Turkish and around $12 \%$ speak Kurdish and around $8 \%$ speak both Kurdish and Turkish. Originally they are immigrant settled down in this land many years ago.

The subjects of the study consist of sixty-four students: thirty monolingual, sixteen bilingual, and sixteen trilingual learners. The difference between the number of the subjects was due to lack of availability of the subjects. The monolingual consists of twenty female and twelve male learners. The bilingual students are nine male and seven female whereas the trilinguals are equal eight boys and eight girls. They are studying English as a foreign language with the aim of passing the TOEFL test. Their native languages were Persian, Persian and Kurdish or Turkish, Persian and Kurdish and Turkish. Their age varies from nineteen to twenty six. 


\subsection{The procedure of the study}

Linguistic activities such as essay-writing usually require learners to express themselves beyond the bounds of the single sentence, and hence to cope with more complex structures and constraints on use. In fact, 'the sentence not only expresses its own meaning but also the multiple links it has with the whole text and communicative context' (van Dijk \& Kintsch, 1983: 285).

Since the beginning of the century scholars of variety of discipline such as psychologists, linguists, neurologists and educators have paid attention to the development of bilinguality. During the recent decade there were research explosion on the issue of trilinguality, varying form carefully documented child biographies to comparative studies of school/university progress with mono, bi, and trilingual learner.

The methodology of the present study has its root in the idea of comparing the groups with the difference of an attempt to analyze their language progress in term of their success in the TOEFL test. At the same time, more attention was paid to the control factors like the socio-economic status of the subjects, and their level of proficiency in the target language which is English before the experiment started. The researcher tried to control all of the parameters to validate the results; however, it is possible that there might be some factors which either were too difficult to be controlled or the researcher were fully unaware about them.

As stated earlier, in an experiment, the researcher tried to find out whether knowing more than one native like language can be of great help in acquiring English as a foreign language after puberty and contributed significantly in passing the TOEFL test or not.

At the first step of this study all of the subjects take part in a pretest. The aim of this step was to identify the participants' level. The test was very much similar to the TOEFL test though significantly easier. Then the subjects were randomly placed in two groups. In each group there were mono, bi, and trilingual learners. Each class includes thirty-two learners. The course lasted for four months. The teaching materials included grammar, reading comprehension and listening comprehension four hours a week each course. The subjects also attended English lab. for several sessions. Then the subjects participated in the TOEFL test.

The result of the pretest gave some idea to the researcher about the subjects' level of proficiency. In the pretest which around sixty-nine subjects participated in it. One of the subjects was extremely good and four were extremely poor consequently they discarded from the study. The study was carried out with sixty-four almost homogenous bilingual, monolingual, and trilingual learners.

\section{Results}

The analysis of learners' progress and their capability in passing the TOEFL test within a group of sixty-four subjects cannot yield to an evident conclusion; consequently, the result of the study as well as the conclusion drawn from it should be treated cautiously. However, this does not necessarily mean that no conclusion can be drawn. There were a lot of fruitful and productive insights drawn from the study which can shed light for the subsequent studies, and provide us with different pieces of information concerning monolingual, bilingual, and trilingual learners.

In sum, the results of this study show that there is not a significant difference between the monolingual, bilingual and trilingual learners learning English as a foreign language. In other words, there is not any relation between having more than one native like language and learning a foreign language.

Table 1 shows the result of the TOEFL test. The score is out of twenty, and the following labels are used: X2 is grammar, $\mathrm{X} 3$ is reading, and $\mathrm{X} 4$ is vocabulary for monolingual learners. $\mathrm{X} 7$ is grammar, $\mathrm{X} 8$ is reading, and $\mathrm{X} 9$ is vocabulary for bilingual and trilingual learners. XX2, XX3, and XX4 show the percentage of each element (grammar, reading, and vocabulary) for monolingual learners, and XX7, XX8, and XX9 show the percentage of the score for bilingual and trilingual learners.

\section{$<$ Table 1 about here $>$}

As the table shows there is not a significant difference between the groups. The averages of the monolingual learners' grammar, reading and vocabulary respectively are 13.15, 13.06, and 11.12; whereas the averages of the bilingual, and trilingual learners' grammar, reading and vocabulary respectively are 12.25, 12.84 and 13.5.

Sheer statistical analysis shows slight differences between the groups. The first group did slightly better in grammar and reading comprehension. The difference between the two groups is extremely low, especially concerning reading comprehension. However, what was different is the superiority of the bilingual and trilingual learners over the monolingual ones in vocabulary. Consequently, it might be possible to infer that knowing more than one language might not contribute in learning grammar and reading comprehension after puberty but it might help in acquiring vocabulary. 
This inference should be treated cautiously due to two factors: first, lack of a great deal of data; second, T-test did not prove this.

Table 2 presents the results of the t-test. It shows that there is not a direct relation between the studied elements of the monolingual, bilingual, and trilingual learners learning English as a foreign language. Moreover, there is a very low correlation between gram1 (monolingual) and gram2 (bilingual and trilingual), and read1 (monolingual) and read2 (bilingual and trilingual). The correlation between voc1 (monolingual) and voc2 (bilingual and trilingual) is higher; though the T-test does not prove the existence of any relation between the studied elements, but t-test indicates a higher correlation between vocabularies.

$<$ Table 2 about here $>$

Despite the fact that the T-tests of both the scores and the percentages prove that there is no direct relation (proved no direct relation) between knowing more than one language and learning English as foreign language during puberty, due to the nature of the studied languages (Persian, Turkish, Kurdish, and English); it is possible to argue that from the result gained from the analysis of the vocabulary test knowing more than one language can contribute in learning vocabularies concerning a target language. This might be more fruitful, if the languages are closely related such as English and French and/or English and German.

\section{Pedagogical Implications}

This section will present a general outlook concerning the pedagogical implication of the study concerning the L3 learners. The material discussed in this paper illustrates only a few parameters in third language acquisition. It shows that the challenge for learners 'is not accuracy alone but meaningful and appropriate use as well' (Larsen-Freeman, 1995, pp. 133). In order for language teaching to cope with these - as well as with many other - problems, changes need to be made both in content (i.e. grammar curricula) and in approach (pedagogy) may be a Local Teacher Guide for multilingual area can help the learners. A guide which help the teacher to consider the peculiarities of the multilingual area. In this regard what learners learn (input) should be geared towards increasing the appropriateness of what they produce (output), that is to say, their 'degree of skill' (Richards, 1985, p. 145) in handling texts plus considering their background.

An adequate model of L3 acquisition should integrate general knowledge of language organization at text-level (see Lyons, 1977). It is clear that the nature of the learning process needs to be reconsidered. Learners need 'to develop a wider view of the sentence as a complex grammatical and rhetorical unit' (Hannay \& Mackenzie, 1990, p. 207). Teachers should also stress 'the subservience of grammatical choices within the sentence to the goal of achieving coherent and meaningful discourse' (Hannay \& Mackenzie, 1990, p. 206).

Assuming that formal accuracy often precedes appropriate use (Bardovi-Harlig, 1992), it would not be feasible for learners to acquire sufficient knowledge both of grammatical categories and of their function or use in one single phase. This means that recycling would be necessary: that is to say, 'introducing one aspect of a form and then returning to the form from time to time for reinforcement and elaboration' (Larsen-Freeman, 1991 (or 1995?), p. 291). This suggests that after the initial description of a certain grammatical category, learners would supplement their basic knowledge of this category with more information, description, illustration, and drills in order to acquire a broader knowledge base for subsequent use.

Classroom exercises should be led towards text (re)construction and organization. This may serve as a good introduction to composition training or assignment (Daiker et al., 1985) in later stages of text creation. Encouraging learners to examine various linguistic options and to become more critical towards organizing their acquired knowledge of the language they are studying.

\section{Summary and Conclusion}

Education, defined as an organized and sustained communication designed to bring about learning (UNESCO, 1976), aims at developing the organization of knowledge and skilled abilities. These goals are attained through the development of literacy and can be viewed as communication skills in an academic environment. In an educational perspective, literacy skills can be viewed as a communication skill in a written mode of verbal transmission (reading and writing) employed by literate societies for effective functioning in a changing socio-ecological setting (Srivastava, 1984).

In this study, the issue of various attitudes of different groups (monolingual, bilingual, and trilingual) of speakers toward learning English as a foreign language was tested. It has been shown that knowing different native like languages does not necessarily contribute in learning another language grammar, reading comprehension or vocabulary; however, it has been realised that it can help in acquiring the vocabulary faster. This depends on the nature of languages. This study 
shows that the trilingual learners whose first languages are Persian, Kurdish, and Turkish do not have a significant superiority over those who have acquired one native language which is Persian when they all try to learn English as a foreign language.

Caution is necessary in interpreting and applying the findings, as it would be an ill advise to view the findings of this study as an absolute end for two reasons; firstly, due to the nature of studied languages, secondly, because of the number of the subjects. However, the findings of this study can provide fruitful insights in many areas of studies especially in language pedagogy and linguistics.

The findings either directly or indirectly deal with the issues of language planning in bilingual/trilingual education and their consequences for learners. Bilingual/trilingual education is connected to social, ideological, pedagogical and psychological factors, which are interacting with each other. From pedagogical perspective, it supports the findings related to Cummins' (1981) and Hamers and Blanc (1983) in which they believe of the idea of immersion (i.e.) it is possible to have school with monolingual and bilingual learners. We can conclude that it is possible to have a class with monolingual, bilingual, and trilingual learners without any problem. Moreover, the findings also show that learning a foreign language is mainly a psychological process such as memory, communication, modes and cognitive styles all should be considered.

From linguistics perspective, the findings support Odlin's (1996) view in which language transfer is an indirect process, since if it takes place directly the effect of trilinguality should be depicted in the superiority of the trilingual learners over the bilingual and monolingual learners. However, it might be argued that, concerning the idea of transfer, the findings are in contrary to those of Ringbom (1987) and Thomas (1989). This might be due to the nature of the languages they studied. They studied Spanish speakers learning English. In addition, it might be possible to infer that transfer is a low process. 


\section{References}

Bloomfield, L. (1935). Language. London: Allen \& Unwin.

Carter, R. \& Nash, W. (1990). Seeing Through Language. Oxford: Blackwell.

Cenoz, J. \& Genesee, F. (Eds.) (1998). Beyond Bilingualism: Multilingualism and Multilingual Education. Clevedon: Multilingual Matters.

Clyne, M. (1997). Some of the things trilinguals do. International Journal of Bilingualism, 1, 95-116.

Cenoz, J. \& Genesee, F. (1998). Psycholinguistic perspectives on multilingual education. In Cenoz, J. \& Genesee, F. (Eds.), Beyond bilingualism and multilingualism and multilingual education. Clevendon: Multilingual, pp. 16-32.

Daiker, D.A., Kerek, A., \& Morenberg M. (Eds.) (1985). Sentence Combining: A Rhetorical Perspective. Carbondale and Edwardsville: Southern Illinois University Press.

Danes, F. (1987). 'On Prague school functionalism in linguistics'. In Dirven, R. and Fried V. (Eds.), Functionalism in Linguistics, pp. 3-38.

Danes, F. (1989). Functional sentence perspective and text connectedness. In Conte, M. E., Petöfi, J.S. \& Sözer E. (Eds.), Text and Discourse Connectedness: Proceedings of the Conference on Connexity and Coherence Urbino, July $16-21$.

Hamer, J. F. \& Blanc, M. H. A. (1989). Bilinguality and Bilingualism. Cambridge: Cambridge University Press.

Hoffmann, C. (1999). 'The status of trilingualism in bilingualism' A paper presented in the International Conference on Trilingualism and Third Language Acquisition. Innsbruck, Austria.

Hoey, M. (1991). Patterns of Lexis in Text. Oxford: Oxford University Press.

Larsen-Freeman, D. (1991). Teaching grammar. In M. Celce-Murcia (Ed.), Teaching English as a Second or Foreign Language (pp. 279-296). Boston: Heinle \& Heinle Publishers.

Larsen-Freeman, D. (1995). On the teaching and learning of grammar: Challenging the myths. In Eckman, F.R., D. Highland, Lee, P.W., Mileham, J. \& Weber, R. R. (Eds.), Second Language Acquisition: Theory and Pedagogy (pp. 131-150). Mahwah, NJ: Lawrence Erlbaum Associates, Publishers.

Lyons, J. (1977). Semantics. Cambridge: Cambridge University Press.

Mackey, W. F. (1962). The description of bilingualism. Canadian Journal of Linguistics, 7, 51-85.

Macnamara, J. (1967). The bilingual's linguistic performance. Journal of Social Issues, 23, 58-77. http://dx.doi.org/10.1111/j.1540-4560.1967.tb00576.x

Ringbom, H. (1987). The Role of the first language in foreign language learning. Clevedon: Multilingual Matters.

Odlin, T. (1996). On the recognition of transfer errors. Language Awareness, 5, 166-178. http://dx.doi.org/10.1080/09658416.1996.9959905

Srivastava, R. N. (1984). Consequences of initiating literacy in the second language. In Coulmas, F. (Ed.), Linguistic Minorities and Literacy. Berlin: Mouton.

Thomas, M. (1989). The Acquisition of English articles by first and second language learners. Applied psycholinguistics, 10, 335-55. http://dx.doi.org/10.1017/S0142716400008663

UNESCO, (1976). International Standarad Classification of Education. Paris: UNESCO.

Webster, M. (1961). Webster's Third New International Dictionary of the English Language. London: Bell \& Sons.

\section{Notes}

Note 1 . The difference between the number of the subjects was due to lack of availability of the subjects.

Note 2. In this study the learners' family background was considered: such the financial status of the family, the parents' level of education, and their jobs. 
Table 1.

\begin{tabular}{|c|c|c|c|c|c|c|c|c|c|c|c|c|}
\hline & $\mathrm{X} 2$ & $\mathrm{X3}$ & $\mathrm{X} 4$ & $\mathrm{X} 7$ & X8 & X9 & $\mathrm{Xx2}$ & $\mathbf{X x 3}$ & $\mathrm{Xx4}$ & $\mathbf{X x} 7$ & Xx8 & Xx9 \\
\hline 1 & 13 & 17 & 16 & 16 & 13 & 16 & .65 & .85 & .80 & .80 & .65 & .80 \\
\hline 2 & 16 & 13 & 14 & 13 & 17 & 14 & .80 & .65 & .70 & .65 & .85 & .70 \\
\hline 3 & 18 & 14 & 19 & 12 & 14 & 15 & .90 & .70 & .95 & .60 & .70 & .75 \\
\hline 4 & 12 & 16 & 15 & 18 & 10 & 16 & .60 & .80 & .75 & .90 & .50 & .80 \\
\hline 5 & 8 & 10 & 12 & 19 & 10 & 9 & .40 & .50 & .60 & .95 & .50 & .45 \\
\hline 6 & 13 & 12 & 14 & 14 & 14 & 7 & .65 & .60 & .70 & .70 & .70 & .35 \\
\hline 7 & 6 & 8 & 9 & 3 & 9 & 11 & .30 & .40 & .45 & .15 & .05 & .55 \\
\hline 8 & 12 & 4 & 6 & 8 & 9 & 14 & .60 & .20 & .30 & .40 & .45 & .70 \\
\hline 9 & 13 & 16 & 16 & 17 & 17 & 17 & .65 & .80 & .80 & .85 & .85 & .85 \\
\hline 10 & 19 & 18 & 17 & 9 & 19 & 18 & .95 & .90 & .85 & .05 & .95 & .90 \\
\hline 11 & 10 & 18 & 10 & 13 & 9 & 17 & .50 & .60 & .50 & .65 & .05 & .85 \\
\hline 12 & 2 & 11 & 13 & 14 & 11 & 18 & .10 & .55 & .65 & .70 & .55 & .90 \\
\hline 13 & 3 & 6 & 8 & 16 & 17 & 9 & .15 & .30 & .40 & .80 & .85 & .45 \\
\hline 14 & 7 & 11 & 11 & 14 & 18 & 11 & .35 & .55 & .55 & .70 & .90 & .55 \\
\hline 15 & 8 & 11 & 11 & 1 & 4 & 14 & .40 & .55 & .55 & .5 & .20 & .70 \\
\hline 16 & 18 & 14 & 13 & 19 & 14 & 15 & .90 & .70 & 65 & .95 & .70 & .75 \\
\hline 17 & 16 & 17 & 19 & 14 & 16 & 16 & .80 & .85 & .95 & .70 & .80 & .80 \\
\hline 18 & 15 & 16 & 12 & 10 & 10 & 17 & .75 & .80 & .60 & .50 & .50 & .85 \\
\hline 19 & 16 & 15 & 14 & 13 & 16 & 16 & .80 & .75 & .70 & .65 & .80 & .80 \\
\hline 20 & 18 & 15 & 11 & 16 & 16 & 16 & .90 & .60 & .55 & .80 & .80 & .80 \\
\hline 21 & 19 & 15 & 11 & 13 & 14 & 9 & .95 & .60 & .55 & .65 & .70 & .45 \\
\hline 22 & 13 & 16 & 16 & 10 & 14 & 10 & .65 & .80 & .80 & .50 & .70 & .50 \\
\hline 23 & 13 & 15 & 14 & 16 & 13 & 12 & .65 & .75 & .70 & .80 & .65 & .60 \\
\hline 24 & 14 & 10 & 11 & 15 & 12 & 18 & .70 & .50 & .55 & .75 & .60 & .90 \\
\hline 25 & 14 & 10 & 9 & 14 & 14 & 19 & .70 & .50 & .45 & .70 & .70 & .95 \\
\hline 26 & 17 & 9 & 8 & 17 & 12 & 15 & .85 & .45 & .40 & .85 & .60 & .75 \\
\hline 27 & 15 & 11 & 11 & 18 & 17 & 15 & .75 & .55 & .55 & .90 & .85 & .75 \\
\hline 28 & 4 & 13 & 10 & 8 & 10 & 18 & .20 & .65 & .50 & .40 & .50 & .90 \\
\hline 29 & 15 & 16 & 11 & 6 & 10 & 14 & .75 & .80 & .55 & .30 & .50 & .70 \\
\hline 30 & 19 & 8 & 4 & 6 & 6 & 10 & .95 & .25 & .20 & .30 & .30 & .50 \\
\hline 31 & 17 & 15 & 3 & 7 & 10 & 8 & .85 & .75 & .15 & .35 & .50 & .40 \\
\hline 32 & 17 & 18 & 9 & 16 & 11 & 14 & .85 & .90 & .45 & .80 & .55 & .70 \\
\hline
\end{tabular}


Table 2 .

\begin{tabular}{|l|l|l|}
\hline & Correlation & T-test \\
\hline Pair1 gram1-gram2 & .028 & .131 \\
\hline Pair2 read1-read2 & .221 & .470 \\
\hline Pair3 voc1-voc2 & .313 & -2.965 \\
\hline Pair 4 gam1\% \& gram2\% & .028 & .131 \\
\hline Pair 5read1\% \& read2\% & .221 & .470 \\
\hline Pair 6 Voc1\% \& Voc2 \% & .313 & -2.965 \\
\hline
\end{tabular}

Table 3.

Paired Samples Statistics

\begin{tabular}{|c|c|c|c|c|c|}
\hline & & Weari & W & Sta. Deviation & $\begin{array}{l}\text { Std. Error } \\
\text { Mean }\end{array}$ \\
\hline \multirow{2}{*}{$\begin{array}{l}\text { Pair } \\
1\end{array}$} & gram1 & 12.813 & 32 & 5.012 & .886 \\
\hline & gram2 & 12.656 & 32 & 4.639 & .820 \\
\hline \multirow{2}{*}{$\begin{array}{l}\text { Pair } \\
2\end{array}$} & read1 & 13.063 & 32 & 3.654 & .646 \\
\hline & read2 & 12.688 & 32 & 3.578 & .633 \\
\hline \multirow{2}{*}{$\begin{array}{l}\text { Pair } \\
3\end{array}$} & voc1 & 11.781 & 32 & 3.816 & .675 \\
\hline & 4002 & 14.000 & 32 & 3.379 & 597 \\
\hline \multirow{2}{*}{$\begin{array}{l}\text { Pair } \\
4\end{array}$} & gram $1 \%$ & .6406 & 32 & .2506 & $4.430 \mathrm{E}-02$ \\
\hline & gram $2 \%$ & .6328 & 32 & .2320 & $4.101 \mathrm{E}-02$ \\
\hline \multirow{2}{*}{$\begin{array}{l}\text { Pair } \\
5\end{array}$} & read $1 \%$ & .6531 & 32 & .1827 & $3.230 \mathrm{E}-02$ \\
\hline & read $2 \%$ & .6344 & 32 & 1789 & $3.163 \mathrm{E}-02$ \\
\hline \multirow{2}{*}{$\begin{array}{l}\text { Pair } \\
6\end{array}$} & woc $1 \%$ & .5891 & 32 & .1908 & $3.373 \mathrm{E}-02$ \\
\hline & voc $2 \%$ & . & 32 & .1690 & $2.987 E-02$ \\
\hline
\end{tabular}

Table 4.

Paired Samples Correlations

\begin{tabular}{|c|c|c|c|c|}
\hline & & $\mathbf{N}$ & Correlation & Big. \\
\hline Pair 1 & gram1 \& gram2 & 32 & .028 & .881 \\
\hline Pair 2 & read1 \& read2 & 32 & .221 & .224 \\
\hline Pair 3 & woc1 \& voc 2 & 32 & .313 & .081 \\
\hline Pair 4 & gram $1 \%$ g gram $2 \%$ & 32 & .028 & .881 \\
\hline Pair 5 & read $1 \%$ \& read $2 \%$ & 32 & .221 & .224 \\
\hline Pair 6 & woc $1 \% 8 \operatorname{woc} 2 \%$ & 32 & .313 & .081 \\
\hline
\end{tabular}


Table 5. Paired Samples Test

\begin{tabular}{|c|c|c|c|c|c|c|c|c|}
\hline & \multicolumn{5}{|c|}{ Paired Differences } & \multirow[b]{3}{*}{ t } & \multirow[b]{3}{*}{$d^{d f}$} & \multirow[b]{3}{*}{ Sigy (2-taledid) } \\
\hline & \multirow[b]{2}{*}{ Mean } & \multirow[b]{2}{*}{ Std. Devilation } & \multirow{2}{*}{\begin{tabular}{|c} 
Sttd. Erofor \\
Mearl
\end{tabular}} & \multicolumn{2}{|c|}{$\begin{array}{l}95 \% \text { Confidence } \\
\text { Interwal of the } \\
\text { cifference }\end{array}$} & & & \\
\hline & & & & Lower & Upper & & & \\
\hline Pair 1 glamlin' - gyam? & .156 & 6735 & 1.191 & -2272 & 2505 & .131 & 31 & .896 \\
\hline Pair 2 peadl - pead2 & 375 & 4.513 & .798 & -1.252 & 20002 & .470 & 31 & .642 \\
\hline Pail $31001-1002$ & -2219 & 4233 & .748 & -3745 & .693 & -2965 & 31 & .006 \\
\hline Pair 4 gram $1 \%$ - gram $2 \%$ & $7.813 E-013$ & .3360 & $5953 \mathrm{E}-02$ & -1136 & .1292 & .131 & 31 & .896 \\
\hline Pair 5 pead $1 \%$ - read $2 \%$ & $1.875 E-012$ & $.25 T$ & $3980-02$ & $-6.26 E-02$ & 1001 & .470 & 31 & .642 \\
\hline Pair 6 voc: $1 \%$ - 100 $2 \%$ & -1109 & .2117 & $3.741 \mathrm{E}-02$ & -.1872 & $-346 \mathrm{E}-02$ & -2965 & 31 & . \\
\hline
\end{tabular}

Table 6. Frequencies

Statistics

\begin{tabular}{|c|c|c|c|c|c|c|c|}
\hline & & graml & readt & 4001 & gram2 & read2 & voc \\
\hline \multirow[t]{2}{*}{ W } & Valió & 32 & 32 & 32 & 32 & 32 & 32 \\
\hline & Missing & 0 & 0 & 0 & 0 & 0 & 0 \\
\hline \multicolumn{2}{|c|}{ Wean } & 12.813 & 13.063 & 11.781 & 12.656 & 12.688 & 14.000 \\
\hline \multicolumn{2}{|c|}{ Wedian } & 13.500 & 14.000 & 11.000 & 14.000 & 13.000 & 15.000 \\
\hline \multicolumn{2}{|c|}{ Stu. Deviation } & 5.012 & 3.654 & 3.816 & 4.639 & 3.578 & 3.379 \\
\hline \multicolumn{2}{|c|}{ Variance } & 25.125 & 13.351 & 14.564 & 21.523 & 12.802 & 11.419 \\
\hline \multicolumn{2}{|c|}{ Sum } & 410.0 & 418.0 & 377.0 & 405.0 & 406.0 & 448.0 \\
\hline
\end{tabular}

Statistics

\begin{tabular}{|c|c|c|c|c|c|c|c|}
\hline & & glame & lead1 \% & $\operatorname{voc} 1 \%$ & glan $2 \%$ & lead2\% & $\operatorname{voc} 2 \%$ \\
\hline \multirow[t]{2}{*}{$\mathbb{N}$} & Valid & 32 & 32 & 32 & 32 & 32 & 32 \\
\hline & Wissing & 0 & 0 & 0 & 0 & 0 & 0 \\
\hline \multicolumn{2}{|c|}{ Mean } & .6406 & .6531 & .5891 & .6329 & .6344 & .7000 \\
\hline \multicolumn{2}{|c|}{ Median } & .6750 & .7000 & .5500 & .7000 & .6500 & .7500 \\
\hline \multicolumn{2}{|c|}{ Std. Deviation } & .2506 & .1827 & .1908 & .2320 & .1789 & .1690 \\
\hline \multicolumn{2}{|c|}{ Variance } & $6.281 E-02$ & $3.338 \mathrm{E}-02$ & $3.641 E-02$ & $5.381 \mathrm{E}-02$ & $3.201 \mathrm{E}-02$ & $2.855 \mathrm{E}-02$ \\
\hline \multicolumn{2}{|c|}{ Sum } & 20.50 & 20.90 & 18.85 & 20.25 & 20.30 & 22.40 \\
\hline
\end{tabular}




\section{Graph}

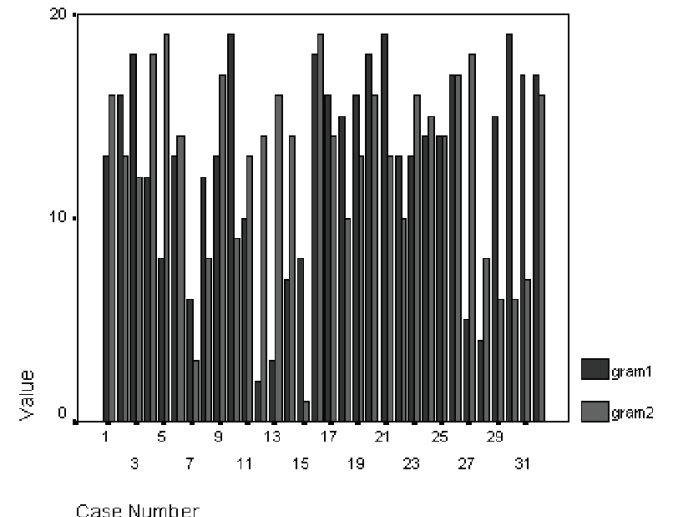

Graph

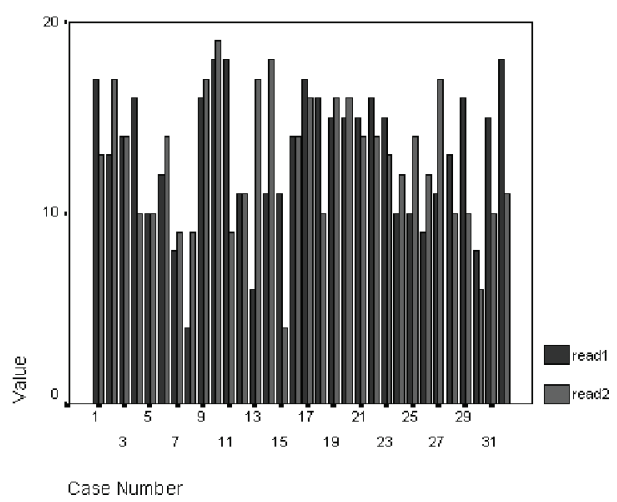

Graph

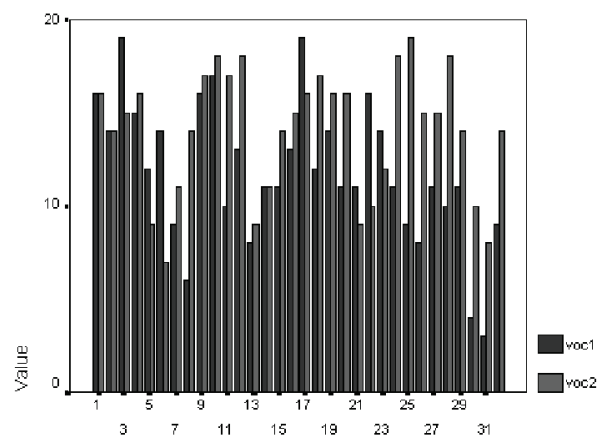

Case Numbe 